\title{
Sea cucumbers-saponin ameliorates hepatorenal toxicity induced by Gentamicin in rats
}

\author{
Ayman Saber Mohamed ${ }^{1,}{ }^{*}$, Mohamed Abdelmohsen Gamal ${ }^{2}$, Emad El-Zayat ${ }^{3}$ and H Suliman ${ }^{4}$ \\ ${ }^{1}$ Physiology- Zoology Department - Faculty of Science - Cairo University -12613, Giza, Egypt. Tel: 01275350954. \\ ${ }^{2}$ Department of biotechnology, University for Modern Sciences and Arts (MSA), Egypt. \\ ${ }^{3}$ Molecular Physiology and Biotechnology, Zoology Department, Faculty of Sciences, Cairo University, Egypt. \\ ${ }^{4}$ Medical Biochemistry, Faculty of Medicine, Alexandria University, Egypt.
}

GSC Biological and Pharmaceutical Sciences, 2021, 14(03), 129-136

Publication history: Received on 01 February 2021; revised on 28 February 2021; accepted on 02 March 2021

Article DOI: https://doi.org/10.30574/gscbps.2021.14.3.0069

\begin{abstract}
Background: Sea cucumbers have number of one of a pharmacological effects counting anticancer, anticoagulant, antiinflammatory, antioxidant, and wound healing. Biological properties and therapeutic benefits of Sea cucumbers can be connected to the presence of a wide cluster of bioactive compounds particularly triterpene glycosides (saponins). Aims: The present study aimed to explore the hepatoprotective and nephroprotective activity of Sea cucumbers-saponin (ScS) on gentamicin-induced hepatorenal toxicity in rats. Main methods: Eighteen male Wistar rats were divided into three groups, control, gentamycin, and gentamycin+ Sc-S. The hepatorenal toxicity model was induced by gentamycin (80 $\mathrm{mg} / \mathrm{kg}$, i.p) for 8 days. Results: The Sc-S group showed a reduction in the concentrations of urea, uric acid, creatinine, MDA and the activities of AST, ALT, and ALP. While it caused a general increase in the levels of CAT and GSH. Microscopic examination appeared a clear enhancement in liver and kidney histology of Sc-S group. Conclusion: The antioxidant activity of Sc-S is the main mechanism for the protection of the liver and kidney against gentamicin toxicity.
\end{abstract}

Keywords: Holothuria Arenicola; Saponin; Gentamycin; Hepatorenal toxicity; Oxidative stress

\section{Introduction}

Aminoglycosides are among the foremost vital compounds utilized to treat genuine diseases caused by aerobic, Gramnegative bacteria. [1]. Regardless their ampleness and their clinical utility for treating bacterial diseases, they have outstandingly profoundly bad side impacts, which include liver and kidney toxicity.[3]. Denamur [4] detailed that aminoglycoside anti-microbials cause intense nephrotoxicity in around 5\% to $25 \%$ within the patients that have taken it. Additionally, an estimation of the patients who gotten aminoglycoside anti-microbials treatment such as gentamicin for over 7 days of almost $8 \%$ to $26 \%$, have demonstrated toxicity within the liver [5]. Gentamicin overdose prompts hepatotoxicity because of the mode of action on enzymatic and non-enzymatic antioxidants, which it suppresses, which leads to the overproduction of reactive oxygen species [6].

Overall examination of marine creatures as wellsprings of new bioactive metabolites revealed the wide dissemination of saponins among marine creatures [7]. Saponins are amphipathic foaming glycosides characterized by having hydrophilic glycoside moieties combined with a lipophilic aglycone [8].They are important bioactive compounds in sea cucumbers. Saponins have antiproliferative [10] antimicrobial [11] antitumor [9] and antioxidant properties [12]. So based on the previously presented studies and data, the present study intended to explore the hepatoprotective and nephroprotective activity of Sea cucumbers-saponin (Sc-S) on gentamicin-induced hepatorenal toxicity in rats.

\footnotetext{
* Corresponding author: Ayman Saber Mohamed

Lecturer of Physiology- Zoology Department - Faculty of Science - Cairo University -12613, Giza, Egypt. Tel: 01275350954.
} 


\section{Material and methods}

\subsection{Materials}

Standard soy saponin was provided by Sigma-Aldrich (St. Louis, MO, USA) with a purity of 90\% and 10\% ash. All chemicals and Kits were purchased from the Biodiagnistic Company (El Moror St, Dokki, EGY).

\subsection{Sample collection and preparation}

Sea cucumber (Holothuria Arenicola) were collected from Abu-Qir Bay in the Egyptian Mediterranean coast at the eastern Alexandrian coast (May-June 2020). The voucher specimens Holothuria (Thymiosycia) arenicola Semper, 1868 (USNME16796, UGI 2387) were deposited at the Zoology department, Faculty of Science, Cairo University, Egypt. The animals were transported to our laboratory in an icebox containing ice cubes and a couple of squeezes of table salt. The animals were quickly washed beneath running tap water, all visceral organs were evacuated and after that, the body walls cut and stored at $-20^{\circ} \mathrm{C}$ until processing.

\subsection{Saponin extraction}

Sea cucumbers were digested with $2 \%$ neutral protease for $4 \mathrm{hrs}$ and an insoluble material was removed by filtration. Polysaccharides from the digest were precipitated by adding $60 \% \mathrm{EtOH}(\mathrm{v} / \mathrm{v})$ of $95 \%$ at $4^{\circ} \mathrm{C}$ overnight, followed by centrifugation at $4500 \mathrm{rpm}$ for $10 \mathrm{~min}$. For separation of saponin, the filtrate was concentrated to 1/5 of its original volume, washed twice with $50 \mathrm{ml}$ of diethyl ether to remove the fat contents using a separatory funnel. It was further extracted three times using $150 \mathrm{ml}$ of water-saturated butanol. The butanol solution was washed twice with $100 \mathrm{ml}$ of distilled water to remove the impurities. The remaining n-butanol solution was transferred to a tarred round bottom flask for evaporation using a rotary evaporator under vacuum at $55^{\circ} \mathrm{C}$.The dry material obtained was saponin. [13].

\subsection{High-performance liquid chromatography (HPLC) Analysis}

HPLC analysis was performed by an Agilent (USA) 1200 Series system equipped using a binary pump (G1312A), a thermostatic column compartment (G1316A), and a diodearray detector (DAD; G4212B). The chromatographic separation was carried out with a Zorbax Eclipse Plus C18 column ( $250 \mathrm{~mm} \times 4.6 \mathrm{~mm}, 5 \mu \mathrm{m}$, Agilent) and an acetonitrilewater mobile phase as the eluent (Gradient elution conditions are as follows: acetonitrile: H20=20:80 to 100:0 over 20 min and then back to $20: 80$ over $5 \mathrm{~min}$ ) at a flow rate of $1.0 \mathrm{~mL} \bullet \mathrm{min}-1$ and $30^{\circ} \mathrm{C}$. Detection and quantification were performed at $215 \mathrm{~nm}$.

\subsection{Animal Housing}

Adult male Wistar albino rats (Rattus norvegicus) weigh ᄀing 150 - 170 g were used in the ongoing study. Animals were purchased from the National Research Centre (NRC), Egypt, grouped and housed in polypropylene cages (six animals /cage) in a well-ventilated animal house at a temperature of $23 \pm 2{ }^{\circ} \mathrm{C}$ within a natural day/night cycle. They were nourished standard chow pellets and drinking water ad libitum. Rats were acclimatized to animal house conditions for 7 days before the start of the study.

Afterward, the animals were divided into three groups; Group I was the control group of rat and they received $1 \mathrm{ml} / \mathrm{kg}$ saline orally. Group II was the model gentamicin group and they received $80 \mathrm{mg} / \mathrm{kg}$ of gentamicin i.p. based on the protocol set by Jabbari et al. [14] for 7 days. Group III was the Saponin treatment group, where the rats received firstly gentamycin for 8 days then administrated Saponin (100 mg/kg) [15] for another 7 days.

\subsection{Animal handling and specimen collection}

At the end of the experimental periods, the rats were anesthetized by intraperitoneal injection sodium pentobarbital (50 mg/kg body weight). The chest was opened and the blood was collected by cardiac puncture. The blood collected from the rats was separated by centrifugation at $3000 \mathrm{rpm}$ for 15 minutes to obtain sera which were stored at $-80^{\circ} \mathrm{C}$ for the biochemical measurements. Liver and kidney were removed and immediately blotted using filter paper to remove traces of blood.

\subsection{Liver and kidney homogenate preparation}

Liver and kidney tissues were homogenized $(10 \% \mathrm{w} / \mathrm{v})$ in ice-cold $0.1 \mathrm{M}$ Tris-HCl buffers (pH 7.4). The homogenate was centrifuged at $860 \times \mathrm{g}$ for 15 minutes at $4 \mathrm{oC}$ and the resultant supernatant was then used for the biochemical analyses. 


\subsection{Biochemical analyses}

The collected sera were used for determining aspartate aminotransferase (AST) and alanine aminotransferase (ALT) by the method of Reitman and Frankel [16], alkaline phosphatase (ALP) [17], creatinine [18], urea [19], uric acid [20], IL-10 and TNF- $\alpha$ [21] according to the manufacturer's instructions using Bio-diagnostic kits (Giza, Egypt).

\subsection{Oxidative stress markers}

The supernatant of the homogenate of the liver and the kidney was used for biochemical analysis according to the manufacturer's instructions using Biodiagnostic kits (Giza, Egypt). MDA level is an index of lipid peroxidation and it was estimated by Ohkawa et al [22] (Colorimetric kit), glutathione reduced (GSH) (Colorimetric kit) and catalase [23] (Kinetic Kit) were determined.

\subsection{Histopathological examination}

Liver and kidney tissues were fixed in 10\% formal saline, then embedded in paraffin and sectioned. Afterward, the sections were stained with haematoxylin and eosin for histological examination using a light microscope.

\subsection{Statistical analysis}

Values were expressed as means \pm SE. The comparisons within groups were evaluated utilizing one-way analysis of variance (ANOVA) with Duncan post hoc test was used to compare the group means and $\mathrm{p}<0.05$ was considered statistically significant. SPSS, for Windows at (version 15.0) was used for the statistical analysis.

\section{Results}

The HPLC studies of saponin shows the peak at retention time $5.25 \mathrm{~min}$. that is matched with the standard saponin confirming the presence of saponin in isolated samples (Fig. 1). The amount of saponin present in HaS were calculated and total percent of saponin was found to be $40.17 \%$.
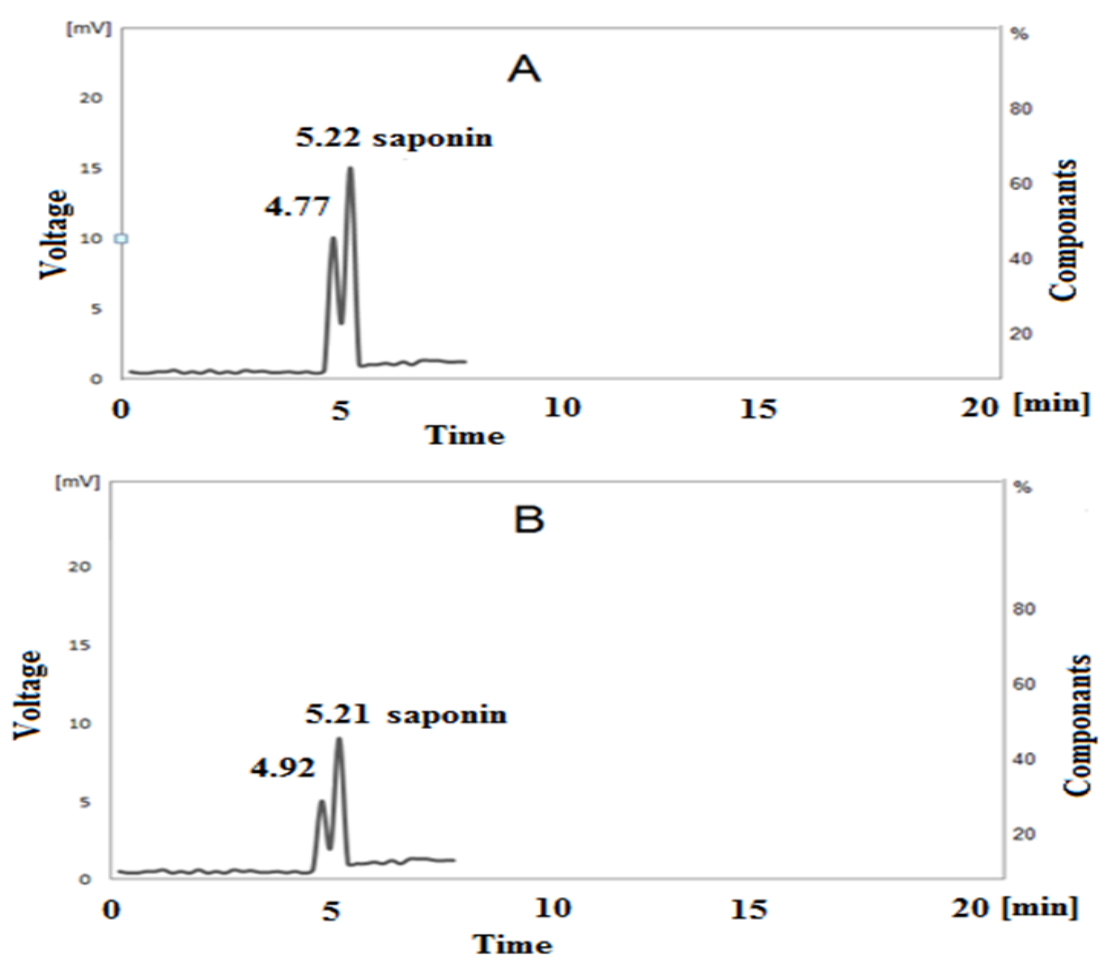

Figure 1 HPLC analysis of standard saponin (A) and saponin extracted from Holothuria Arenicola (B). 


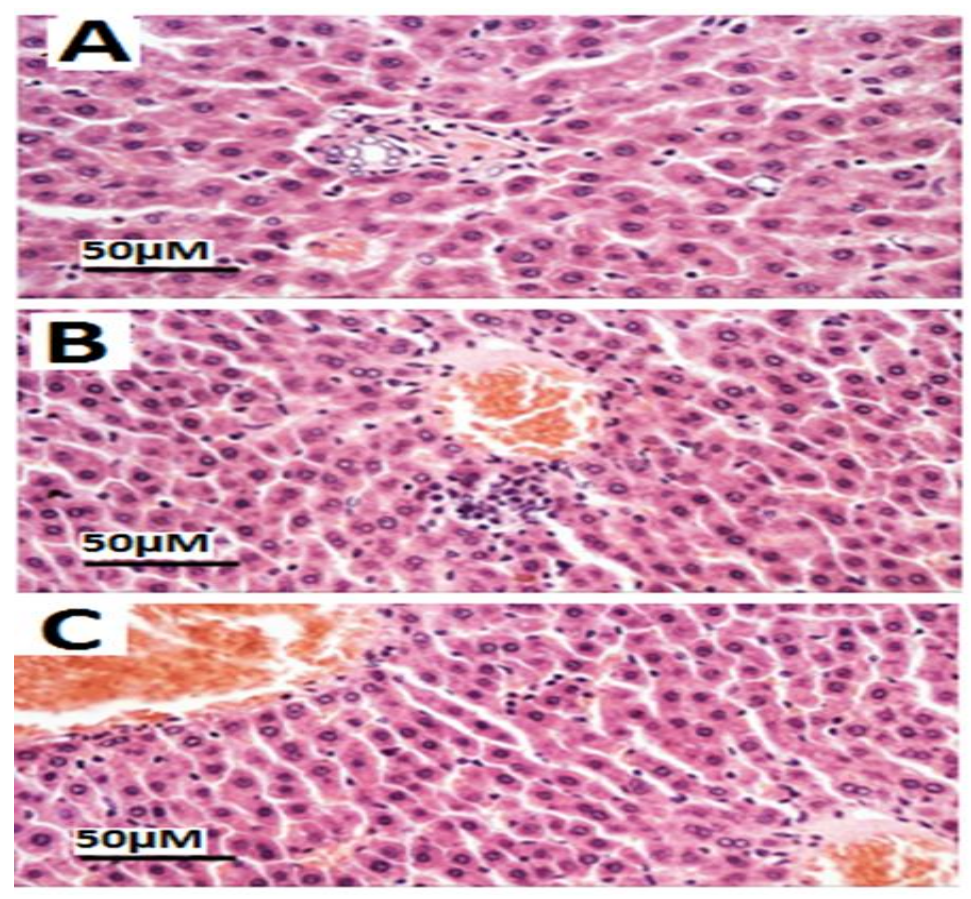

Figures 2 Showing results obtained from the histopathological test of liver samples. A represent the control samples, $\mathrm{B}$ represent the GM samples and C represent the Saponinin samples.

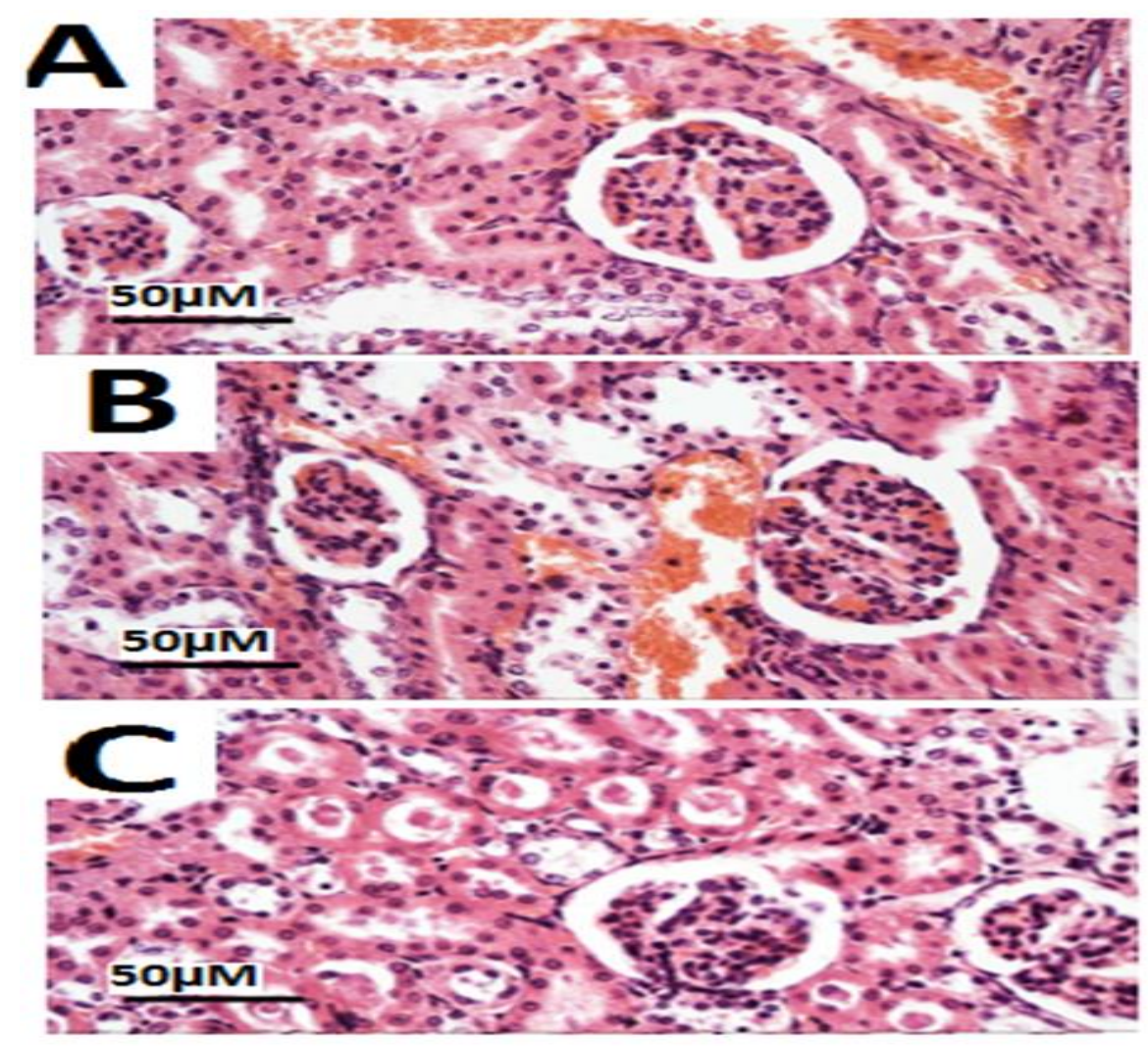

Figure 3 Showing results obtained from the histopathological test of kidney samples. A represent the control samples, $\mathrm{B}$ represent the GM samples and $\mathrm{C}$ represent the Saponinin samples 
A significant increase $(\mathrm{p}<0.05)$ in AST, ALT and ALP activities was noticed in GM group as compared with the control group. On the other hand, these enzyme activities decreased significantly $(\mathrm{p}<0.05)$ after the treatment with Saponin as compared with GM group. (Table 1)

Table 1 Effect of Saponin on liver function parameters of gentamicin induced hepatorenal toxicity in rats.

\begin{tabular}{|l|l|l|l|}
\hline Groups & AST (U/ml) & ALT (U/ml) & ALP (IU/L) \\
\hline Control & $79.16 \pm 1.57^{\mathrm{a}}$ & $34.86 \pm 0.53^{\mathrm{a}}$ & $149.35 \pm 1.94^{\mathrm{a}}$ \\
\hline GM & $106.41 \pm 1.12^{\mathrm{c}}$ & $48.17 \pm 0.87^{\mathrm{c}}$ & $202.24 \pm 2.32^{\mathrm{c}}$ \\
\hline Saponin & $96.49 \pm 0.73^{\mathrm{b}}$ & $40.54 \pm 0.42^{\mathrm{b}}$ & $159.39 \pm 2.33^{\mathrm{b}}$ \\
\hline
\end{tabular}

Table 2 showed a significant increase $(\mathrm{p}<0.05)$ in creatinine, urea and uric acid concentrations of GM group as compared with the control group. While the treatment with Saponin caused a significant decrease $(\mathrm{p}<0.05)$ in creatinine urea and uric acid concentration as compared with GM group.

Table 2 Effect of Saponin on kidney function parameters of gentamicin induced hepatorenal toxicity in rats.

\begin{tabular}{|l|l|l|l|}
\hline Groups & Urea (g/dl) & Creatinine $(\mathbf{m g} / \mathbf{d l})$ & uric acid $\mathbf{( m g / d l )}$ \\
\hline Control & $40.56 \pm 1.42^{\mathrm{a}}$ & $1.54 \pm 0.07^{\mathrm{a}}$ & $1.75 \pm 0.09^{\mathrm{a}}$ \\
\hline GM & $61.00 \pm 1.51^{\mathrm{c}}$ & $3.30 \pm 0.07^{\mathrm{c}}$ & $6.63 \pm 0.33^{\mathrm{c}}$ \\
\hline Saponin & $44.99 \pm 1.27^{\mathrm{b}}$ & $2.40 \pm 0.04^{\mathrm{b}}$ & $4.03 \pm 0.18^{\mathrm{b}}$ \\
\hline
\end{tabular}

Values are given as means for 6 rats per group.

Each value not sharing a common letter superscript is significantly different $(\mathrm{P}<0.05)$.

Data recorded in table 3 represent a significant increase $(\mathrm{p}<0.05)$ in MDA concentration while GSH and CAT levels decreased significantly in GM group as compared with the control group. Rat treated with Saponin showed a significant decrease $(\mathrm{p}<0.05)$ in MDA concentration while GSH and CAT levels increased significantly as compared with GM group.

Table 3 Effect of Saponin on oxidative stress parameters of gentamicin induced hepatorenal toxicity in rats.

\begin{tabular}{|l|l|l|l|l|l|l|}
\hline \multirow{2}{*}{ Groups } & \multicolumn{2}{l|}{ MDA (nmol/gm. tissue) } & \multicolumn{2}{l|}{ GSH (mg/g. tissue) } & \multicolumn{2}{l|}{ CAT (U/g. tissue) } \\
\cline { 2 - 7 } & Liver & Kidney & Liver & Kidney & Liver & Kidney \\
\hline Control & $0.94 \pm 0.05^{\mathrm{a}}$ & $1.00 \pm 0.07^{\mathrm{a}}$ & $2.90 \pm 0.19^{\mathrm{b}}$ & $5.15 \pm 0.20^{\mathrm{b}}$ & $25.43 \pm 0.71^{\mathrm{c}}$ & $16.58 \pm 0.42^{\mathrm{c}}$ \\
\hline GM & $1.57 \pm 0.03^{\mathrm{c}}$ & $1.49 \pm 0.02^{\mathrm{c}}$ & $1.57 \pm 0.06^{\mathrm{a}}$ & $2.97 \pm 0.26^{\mathrm{a}}$ & $15.07 \pm 0.599^{\mathrm{a}}$ & $8.96 \pm 0.51^{\mathrm{a}}$ \\
\hline Saponin & $1.24 \pm 0.06^{\mathrm{b}}$ & $1.20 \pm 0.05^{\mathrm{b}}$ & $2.73 \pm 0.01^{\mathrm{b}}$ & $4.75 \pm 0.20^{\mathrm{b}}$ & $19.43 \pm 0.83^{\mathrm{b}}$ & $12.74 \pm 0.38^{\mathrm{b}}$ \\
\hline
\end{tabular}

Each value not sharing a common letter superscript is significantly different $(\mathrm{P}<0.05)$.

The figure A showing the control group of the histopathological test that were conducted on the liver that are showing normal morphological features of hepatic parenchyma with almost intact radiating hepatocytes and intact vasculatures without abnormal tissue alterations or changes. In the meanwhile, figure B is showing the effects of the gentamicin on the model group of mice's livers, where they all showed alternated areas of degenerative changes of hepatocytes in pericentral and periposrtal zones with records of inflammatory cells infiltration. Moreover, shown above in figure $\mathrm{C}$ histological results show mild treatment effects of the Saponin; however, minimal records of inflammatory cells infiltration were observed.

\section{Discussion}

In the present study, the administration of gentamicin for 8 days led to damage in the liver, which affirmed by increment AST, ALT ALP, MDA as well as diminish GSH and CAT levels and histopathological examination. The exacerbated increase of lipid peroxidation by gentamicin impairs membrane lipids and causes hepatocyte necrosis and damage [25]. 
Expanded generation of ROS, which can be seen after the use of gentamicin in cells, is effective in inducing toxic effects of this medication on the structure and capacity of the liver [26]. One the other hand several studies have publicized that hepatoprotective effects are related to Phyto extracts rich in natural triterpenoid saponins [27,28]. Saponin structure and capacity of the liver antioxidant, anti-inflammatory effects and regulating related apoptosis proteins in the liver [29]. The antioxidant activity confirmed by the significant increase in GSH and CAT levels within the treated rats.

Gentamicin induced a typical pattern of nephrotoxicity that was related to noteworthy increment in serum creatinine, urea, and uric acid. Besides, gentamicin induces oxidative stress and histological damage in the kidney. There are many suggested mechanisms by which gentamicin prompt renal damage. These include binding to anionic phospholipids and changing the capacity and structure of cellular and intra-cellular membranes [30], ATP exhaustion from either mitochondrial damage or direct inhibition of mitochondrial oxidative phosphorylation, [31] and it may cause oxidative damage [32]. GM mechanism of nephrotoxicity occurs due to a massive aggregation of the administered gentamicin in the lysosomes [4]. The antioxidant activity of sea cucumbers-saponin (Sc-S) [54] was the reason behind its restoration capacity of the antioxidant system. The treatment by Sc-S ameliorated liver and kidney toxicity via inhibiting oxidative stress, inflammation, and apoptosis [33].

\section{Conclusion}

The antioxidant activity of sea cucumbers-saponin is the main mechanism for the protection of the liver and kidney against gentamicin toxicity.

\section{Compliance with ethical standards}

\section{Acknowledgments}

The authors extend their appreciation to the Deanship of Scientific Research at Faculty of Science, Cairo University, Egypt for supporting the current work.

\section{Disclosure of conflict of interest}

The authors declare that they have no conflict of interest.

\section{Statement of ethical approval}

Experimental protocols and procedures used in this study were approved by the October University for Modern Sciences and Arts, Faculty of Biotechnology, Institutional Animal Care and Use Committee (IACUC) (Egypt). All the experimental procedures were carried out in accordance.

\section{References}

[1] Magnet S, Blanchard JS. Molecular insights into aminoglycoside action and resistance. Chem Rev. 2005; 105(2): 477-498.

[2] Prokhorova I, Altman R, Djumagulov M, Shrestha J, Urzhumtsev A, Ferguson A, Chang CT, Yusupov M, Blanchard SC, Yusupova G. Aminoglycoside interactions and impacts on the eukaryotic ribosome. Proc Natl Acad Sci U S A. 2017; 114(51): E10899-E10908.

[3] Denamur S, Tyteca D, Marchand-Brynaert J, Van Bambeke F, Tulkens P, Courtoy P, Mingeot-Leclercq M. Role of oxidative stress in lysosomal membrane permeabilization and apoptosis induced by gentamicin, an aminoglycoside antibiotic. Free Radical Biology And Medicine. 2011; 51(9): 1656-1665.

[4] Chandel S, Sahu R. Protective effect of dietary inclusion of Aegle marmelos fruit on gentamicin induced hepatotoxicity in rats. Intl J Green Pharm. 2017; 11(3): 597-603.

[5] Almohawes Z. Protective Effect of Melatonin on Gentamicin Induced Hepatotoxicity in Rats. J Pharm Tox. 2017; 12(3): 129-135.

[6] Khattab RA, Elbandy M, Lawrence A, Paget T, Rae-Rho J, Binnaser YS, Ali I. Extraction,Identification and Biological Activities of Saponins in Sea Cucumber Pearsonothuria graeffei. CCHTS. 2018; 21(3): 222-231. 
[7] Osbourn A, Goss RJ, Field RA. The saponins: polar isoprenoids with important and diverse biological activities. Nat Prod Rep. 2011; 28: 1261-1268.

[8] Tian F, Zhang X, Tong Y, Yi Y, Zhang S, Li L, Sun P, Lin L, Ding JP. a new sulfated saponin from sea cucumber, exhibits anti-angiogenic and anti-tumor activities in vitro and in vivo. Cancer Biol Ther. 2005; 4(8): 874-882.

[9] Adibpour N, Nasr F, Nematpour F, Shakour A, Ameri A. Antibacterial and antifungal activity of Holothuria leucospilota isolated from Persian Gulf and Oman Sea. Jundishapur J Microbiol. 2014; 7(1): 8708.

[10] Moghimipour E, Kooshapour H, Rezaee S, Khalili S, Handali S. In vitro cholestrol binding affinity of total saponin extracted from Glycyrrhiza glabra. Asian J Pharm Clin Res. 2014; 7(1): 170-173.

[11] Ashafa A, Nafiu M. Antioxidant and inhibitory effects of saponin extracts from Dianthus basuticus Burtt Davy on key enzymes implicated in type 2 diabetes In vitro. Pharmacognosy Magazine. 2017; 13(52): 576.

[12] Kwon JH, Jacqueline MR, Belanr JR, Pare J, Yaylayan VA. Appli- cation of the microwave-assisted process (MAPTM) to the fast extraction of ginseng saponins.. Food Research International. 2003; 36: 491-498.

[13] Jabbari M, Rostami Z, Jenabi A, Zahedi-Shoolami L, Mooraki A. Simvastatin Ameliorates Gentamicin-Induced Renal Injury in Rats. Saudi J Kidney Dis Transpl. 2011; 22(6): 1181-1186.

[14] Sathyanath R, Hanumantha Rao BR, Kim HG, Cho JH, Son CG. Saponin and non-saponin fractions of red ginseng ameliorate cisplatin-induced pica in rats. Pharm Biol. 2013; 51(8): 1052-1060.

[15] Reitman SS, Frankel A. A colorimetric method for the determination of serum glutamic oxalacetic and glutamic pyruvic transaminases. Am. j. clin.l pathol. 1957; 28: 56-63.

[16] Belfield A, Goldberg DM. Normal ranges and diagnostic value of serum $5^{\prime}$ nucleotidase and alkaline phosphatase activities in infancy. Arch. disease childhood. 1971; 46: 842-486.

[17] Schirmeister J. Determination of creatinine in serum. Dtsch Med Wschr. 1964; 89: 1940.

[18] Fawcett JK, Soctt JE. A rapid and precise method for the determination of urea. J Clin Pathol. 1960; 13: 156-159.

[19] Barham D, Trinder P. An improved colour reagent for the determination of blood glucose by the oxidase system. Analyst. 1972; 151: 142-145.

[20] Van der Linden MW HTSDWR. Determination of tumor necrosis factor-alpha and interleukin-10 production in whole blood stimulation system: assessment of laboratory error and individual variation. J Immunol Methods. 1998; 21: 63-71.

[21] Ohkawa H, Ohishi N, Yagi K. Assay for lipid peroxides in animal tissues by thiobarbituric acid reaction. Anal.Biochem. 1979; 95: 351-358.

[22] Aebi H. Catalase in vitro. Methods enzymol. 1984; 105: 121-126.

[23] Galaly SR, Ahmed OM, Mahmoud AM. Thymoquinone and curcumin prevent gentamicin-induced liver injury by attenuating oxidative stress, inflammation and apoptosis. Journal of physiology and pharmacology. 2014; 65(6): 823-832.

[24] Erin E, Battin J. Sulfur and selenium: A Review of reactiveOxygen species scavenging, glutathione peroxidase and metal-binding antioxidant mechanisms. Cell Biochem Biophys. 2009; 55: 1-23.

[25] Hong J, Kim S, Kim HS. Hepatoprotective effects of soybean embryo by enhancing adiponectin-mediated AMPactivated protein kinase $\alpha$ pathway in high-fat and high-cholesterol diet-induced nonalcoholic fatty liver disease. J med food. 2016; 19: 549-559.

[26] Zheng YF, Wei JH, Fang SQ, Tang YP, Cheng HB, Wang TL, Li CY, Peng GP. Hepatoprotective Triterpene Saponins from the Roots of Glycyrrhiza inflata. Molecules. 2015; 20(4): 6273-6283.

[27] Qu L, Xin H, Zheng G, Su Y, Ling C. Hepatoprotective Activity of the Total Saponins from Actinidia valvata Dunn Root against Carbon Tetrachloride-Induced Liver Damage in Mice. Evid Based Complement Alternat Med. 2012; 216061.

[28] Ramsammy S, Kaloyanides SJ. Effect of gentamicin on the transition temperature and permeability to glycerol of phosphatidylinositol-containing liposomes. Biochem Pharmacol. 1987; 36(7): 179-181.

[29] Weinberg JM, Humes HD. Mechanisms of gentamicin-induced dysfunction of renal cortical mitochondria. I. Effects on mitochondrial respiration. Arch Biochem Biophys. 1980; 205(1): 222-231. 
GSC Biological and Pharmaceutical Sciences, 2021, 14(03), 129-136

[30] Walker PD, Barri Y, Shah SV. Oxidant mechanisms in gentamicin nephrotoxicity. Ren Fail. 1999; 21(3-4): 433442.

[31] Li W, Yan MH, Liu Y, Liu Z, Wang Z, Chen C, Zhang J, Sun YS, Ginsenoside R. ameliorates cisplatin-induced nephrotoxicity in mice through inhibition of inflammation, oxidative stress, and apoptosis. Nutrients. 2016; 8: 566. 